\title{
18. Zen'emon Nakamura, the Japanese Originator of a Special Thermometer for Sericulture.
}

\author{
By Seiji Nakamura.
}

(Comm. Feb. 12, 1952.)

The town of Yanagawa in Hukusima Prefecture has long been noted as one of the centers for the production of silkworm-eggcards, and its products have been widely distributed over northeastern Japan. The Nakamura family, who have been living there from the beginning of the 16 th century until the present, through 14 generations, also have been engaged in this work. The current head of the family is called by the hereditary name of Saheiji Nakamura. It is known that in about 1845, the branch office of the 11th Saheiji exchanged vast amounts of eggcards with Italian merchants at the port of Hakodate, and afterward they were widely exported to European markets.

Now the man, who first made for and applied thermometers to the culture of silkworms, was Zen'emon Nakamura, a younger brother of the 8th Saheiji. At 1839, when he fell ill, and consulted Sōan Inasawa, the court physician to the local feudal Lord of Nihonmatu, Sōan used a fever thermometer to measure the body temperature of his patient, for Sōan had learned the use of this instrument from his famous teacher Dr. von Siebold during his study of European diagnostics in Nagasaki. Zen'emon thus experienced such a diagnosis for the first time, and his curiosity was at once strongly excited, and he was inspired to try to use this instrument to measure the temperature of the culture room, and to control the growth of silkworms. He listened eagerly to the explanation of the function of an ordinary mercurial thermometer from Sōan, and begged him to get one for him through Siebold at Nagasaki. After about three months, a sample arrived for him, and he at once began to study the use of this instrument in the culture room, and was deeply convinced of its trustworthiness. The instrument was, however, too costly and too slow to obtain from the meager supply in it to put it into general use. At last in 1840, he determined to make thermometers himself and to distribute them among his fellow cultivators, and thereby further the promotion of the art and practice of sericulture in general.

It was a great pity that Zen'emon in that small town of Yanagawa remote from cultural centers, about 100 years ago, quite ignorant of glass-working, had nobody to give him scientific advice except 
Sōan, and had no book to consult. He managed first to get a quantity of mercury, but could not obtain glass tubes. So he went to Yedo (now Tōkyō), and visited Kagaya, a wholesale dealer in glass-mirrors, and with his assistance he succeeded in obtaining a hundred glass tubes for thermometers and returned home. Then his zealous and almost fanatical endeavore to make a mercurial thermometer begun. But he could not introduce any mercury into the tube. After a long succession of vain trials, he arrived at the method still employed by physicists and thermometer manufacturers. With this method, the open end of the tube is inserted into a pool of mercury, and then the bulb is heated to a fair degree, whereupon the air within the bulb expands, and escapes through the mercury into the open air. Then the bulb is cooled and mercury enters the stem, and eventually a small quantity reaches the bulb. When the bulb is heated again, mercury vapor is generated, and the air left within the bulb is expelled by this vapor, so that when the bulb is again cooled, an even greater quantity of mercury enters the bulb. Thus when these alternate processes of heating and cooling have been repeated several times, the bulb is at last completely filled with mercury. This method, though simple at first sight, it really requires great skill. By this method, Zen'emon succeeded in making his first thermometer. He then determined the positions of the standard points of freezing and boiling, and graduated the tube by dividing the interval between the two points equally according to the Fahrenheit scale. He was glad to see his first thermometer working exactly in the same manner as the sample from Siebold.

But unfortunately, Zen'emon then met another quite unexpected difficulty. When he manufactured many thermometers and compared them, they did not agree in their indications for intermediate temperatures. When many thermometers were placed at the same time in a water-bath with a certain definite temperature, Zen'emon was perplexed to find that the reading of one thermometer was higher than another thermometer, but lower than a third. This discrepancy was caused by the non-uniformity of the bores of the tubes. When the internal diameters of the tube varies at different places, equal length along the stem does not mean equal expansion of volume of mercury, that is to say, an equal rise of temperature does not follow. After close examinations, Zen'emon recognized the fact, that the essential condition for a good reliable thermometer was the uniformity of the internal diameter of the tube. So he went again to Kagaya, and there he himself superintended the glassblowers in the making of absolutely uniform tubes. After 6 months of this streneous labor, he had produced a large stock of uniform 
tubes, and with these he returned home. Thus he had been able to manufacture a lot of thermometers to be distributed among interested cultivators. He published a small pamphlet explaining the use of the new instrument. This was done in 1849, about 10 years after his first determination to make a thermometer to be used for sericulture.

Besides giving the standard points of the boiling and the freezing temperatures of water, Zen'emon added, for the convenience of cultivators, the following three points on the graduation scale called "quick culture", "medium culture", and "slow culture" at $80^{\circ} \mathrm{F}$. $75^{\circ} \mathrm{F}$., and $70^{\circ} \mathrm{F}$. respectively. In other words, when the culture room is kept at $80^{\circ} \mathrm{F}$., silkworms have a great appetite and the development is very rapid requiring only 27 or 28 days from the first hatching of eggs to the stage of cocoon making. In this case, however, constant care is required in regard to the feeding of mulberry leaves and supervision of other minute operations on the part of cultivators, and it can be said to be a rather dangerous method. When the culture room is kept at $75^{\circ} \mathrm{F}$., it is the most adequate and favorable temperature for silkworms. Their appetite is moderate and development healthy, requiring 32 or 33 days. This method may be said to be the normal method for sericulture. On the other hand, the slow culture at $70^{\circ} \mathrm{F}$, is too tedious requiring 37 or 38 days. These temperature ranges were established by Zen'emon through his careful investigations, and they were henceforth accepted by other cultivators.

Zen'emon had no son nor anybody among his relatives to succeed him in the manufacture of this special thermometer. The work was taken up by Hanzaburo Taguti in the same town. Hanzaburo was also a zealous investigator of sericulture. He afterward made alcohol thermometers for common use.

In conclusion, I should say that Zen'emon's keen observation of the function of a mercurial thermometer in order to utilize it for sericulture, and firm determination to manufacture them for general use, and his endeavor for the fulfilment of this desire ought to be highly appreciated. His scientific spirit and his work at the time of the early dawn of western science among us, must be carefully noted and recorded as an important factor in the history of the scientific development of Japan. 